\title{
APLIKASI EFEK GAYA APUNG DENGAN MOMEN PEMBALIK PADA MODEL TANGKI RANCANGAN UNTUK MENGHEMAT KONSUMSI DAYA POMPA PADA SISI DISCHARGE
}

\author{
Mohammad Galbi ${ }^{1}$, Ishak A $^{2}$ \\ Program Studi Teknik Mesin, Universitas Pembangunan Nasional “Veteran” Jakarta, Jakarta Selatan ${ }^{12}$ \\ Email: galbi_m@yahoo.com
}

\begin{abstract}
The use of the tank as well as a container or tank of liquid reserves to make use of the tank as a necessity. By using its own tank design model which is technically very possible to make the pressure in the tank is less than atmospheric pressure so that the tank will take some role pump connected in series are used for the purpose of improving high pressure. Thus the pressure in the tank is smaller than the atmospheric pressure is only generated from the process flow itself will save pump power required on the press. To prevent the air pressure in the tank exceeds the atmospheric pressure relief valve on the tank supplied air to the atmosphere. The more water into the tank, the greater the downward thrust force due to the weight of water and by the buoy to the piston in fixed position, the tank will move downward relative to the piston. The pressure in the tank due to the movement of the closed tube will follow the phenomenon of negative pressure. To get a larger volume of air or spring difleksi rate greater then the pole float should be as light as possible and frictional forces as small as possible.

The goal is to produce a prototype tank that can lighten the pump working in particular on the discharge side so it can be input pump power savings. The calculations show that a high hit on the side of the press can be reduced upto 100 percent even including reducing losses on the discharge side by enlarging the capacity of the tank. Thus happen electricity savings of the power required on the discharge side of the pump to drain the water into the tank. With spring replacement inverting the inversion moment will produce a higher pressure suction force behind the rise of the spring. Keyword; Tanks, head, discharge, save, Electricity, power, Moment.
\end{abstract}

\section{PENDAHULUAN}

\section{Latar Belakang Masalah}

Proses pengisian tangki penampung atau tangki cadangan dari pompa yang diterapkan selama ini adalah dengan mengupayakan agar tekanan yang ada dalam tangki sama dengan tekanan atmosfir, agar tidak ada tambahan tekanan yang terjadi. Dengan menggunakan tangki model rancangan sendiri ini yang mana secara teknis sangat dimungkinkan untuk menjadikan tekanan dalam tangki kurang dari tekanan atmosfir sehingga tangki ini akan mengambil sebagian peran pompa yang dihubungkan secara seri yang digunakan untuk tujuan meningkatkan tinggi tekan. Dengan demikian tekanan dalam tangki yang lebih kecil dari tekanan atmosfir yang hanya dihasilkan dari proses aliran itu sendiri akan menghemat daya pompa yang diperlukan pada sisi tekan. Usulan tulisan ini pengembangan dari usulan sebelmnya adalah untuk menguji model terhadap efektifitas kerja sistem yang terdiri dari pelampung, torak dan pegas pembalik digantikan oleh efek momen lengan. Selama proses pengisian tangki oleh zat cair hingga terisi penuh sesuai dengan kapasitas yang diharapkan bersama pelampung akan mendorong tangki kebawah dan piston yang bersifat tetap menciptakan vakum pada ruang yang tersisa didalam tangki akibat beban tangki yang terus bertambah. Parameter-parameter yang menentukan besaran vakum berupa berat air, gaya apung, gesekan torak, berat tiang pelampung dan gaya pegas pembalik yang akan diganti dengan lengan pembalik harus diuji lagi untuk menghasilkan tangki prototipe yang memiliki kemampuan menghasilkan tekanan vakum dalam tangki yang optimum dengan gaya pembalik yang memiliki nilai efektifitas yang lebih baik. Untuk melengkapi kerja tangki prototype tersebut dengan tetap disertai pengembangan lanjut berupa pengaturan on-off pompa secara otomatis termasuk pemilihan material yang paling sesuai untuk optimasi kerja sistem tangki. Untuk mencapai tujuan akhir berupa penghematan konsumsi energi maka keluaran tahap kedua (tahap akhir) dari Tulisan ini berupa tangki prototype yang telah teruji lengkap dengan sistem pengaturannya.

\section{Perumusan Masalah}

Ketika air disuplai dari pompa menuju tangki maka perlahan volume air yang masuk kedalam tangki yang bertekanan atmosfir akan mengisi ruang yang 
berisi udara. Untuk mencegah tekanan udara dalam tangki melebihi tekanan atmosfir maka pada tangki disediakan katup pelepas udara ke atmosfir. Semakin banyak air yang masuk kedalam tangki maka semakin besar pula gaya dorong kebawah akibat berat air dan oleh pelampung terhadap piston pada kedudukan tetap, maka tangki akan bergerak kebawah relatif terhadap piston. Gaya dorong inilah yang akan menciptakan ekspansi volume udara yang ada dalam tangki. Agar diperoleh batas gaya dorong keatas maksimum oleh pelampung, maka berat air yang dipindahkan akan sama dengan gaya dorong pelampung terhadap torak dimana isi air pada tangki harus lebih besar dari volume pelampung itu sendiri. Tekanan dalam tangki akibat pergerakan tabung tertutup akan mengikuti fenomena tekanan negatif yaitu volume air yang masuk sama dengan volume udara yang keluar ditambah dengan volume udara yang terjadi akibat berat air ditambah dengan volume akibat dorongan tiang gaya apung. Dengan demikian laju difleksi pegas pembalik kebawah harus lebih besar dari pada peningkatan laju tinggi air pada tangki. Untuk mendapatkan volume udara yang lebih besar atau laju difleksi pegas yang lebih besar maka tiang pelampung harus seringan mungkin dan gaya gesek sekecil mungkin. Untuk mengantisipasi penciutan tangki perlu penerapan cincin fleksibel seperti pada piston motor pembakaran dalam. Untuk itu yang harus diketahui adalah berapa besar rata-rata tekanan negatif yang diperoleh dari gaya guna yang dihasilkan oleh berat air dan pelampung untuk meringankan kerja pompa.

\section{Tujuan}

Tulisan ini bertujuan untuk menghasilkan tangki protipe yang mampu meringankan kerja pompa khususnya meningkatkan head tekan pompa (pada sisi discharge) sehingga dapat dilakukan penghematan daya input pompa hingga sebesar daya yang diperlukan pada sisi dischargenya disesuaikan dengan dimensi tinggi tangki dan pelampung. Keluaran alat ini diharapkan akan menggantikan peran tangki air rumah tangga, hotel, tangki penampung zat cair pada pabrik-pabrik maupun lapangan migas sebagai tangki hemat energi yang dapat diandalkan.

\section{TINJAUAN PUSATAKA}

Hukum Archimedes [1] Hukum Archimedes berhubungan dengan gaya berat dan gaya ke atas suatu benda jika dimasukan kedalam air yaitu "Suatu benda yang dicelupkan sebagian atau seluruhya kedalam zat cair akan mengalami gaya ke atas yang besarnya sama dengan berat zat cair yang dipindahkan oleh benda tersebut”. Hukum Boyle [2] Tekanan dan Volume dari suatu gas adalah berbanding terbalik pada masa gas dan suhu yang konstan (isotermis), yang berarti bahwa tekanan naik, volume turun dan sebaliknya volume naik dan tekanan turun.

\section{Gaya apung}

Menurut [1] menjelaskan bahwa: "Suatu benda yang dicelupkan seluruhnyaatau sebagian kedalam flulida akan mengalami gaya ke atas yang sama dengan berat fluida yang dipindahkannya (Gambar 1)
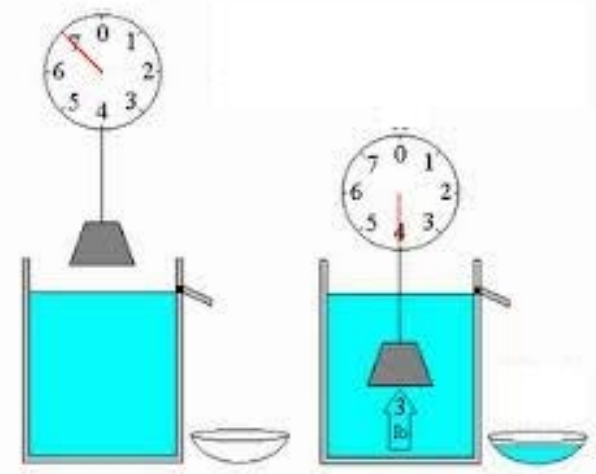

$\mathbf{3} \mathbf{~ k g}$ air yang dipindahkan

Gambar 1. Gaya benda yang dicelupkan

\section{Benda Mengapung}

Bila benda dicelupkan ke dalam air maka ada tiga kemungkinan yang akan dialami oleh benda tersebut, yaitu mengapung, melayang dan tenggelam [3]. Suatu benda dikatakan terapung dalam zat cair bila sebagian benda tercelup dan sebagian lagi muncul di udara, dengan kata lain benda akan terapung diatas permukaan air bila massa jenis benda lebih kecil dari massa jenis zat cair (Gambar 2)

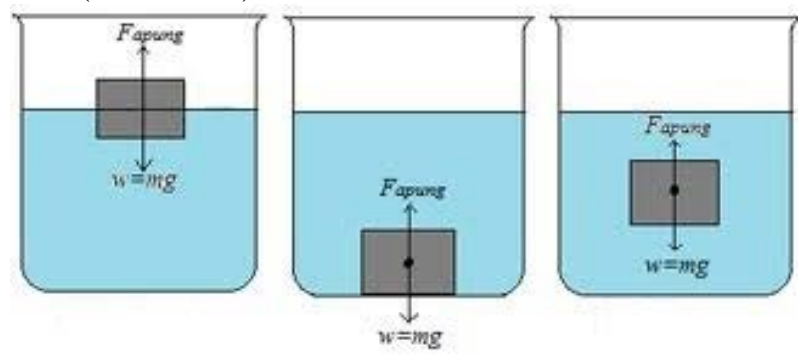

Gambar 2. Benda mengapung

Berdasarkan hukum Archimedes bahwa besarnya gaya keatas yang dikerjakan fluida pada benda adalah sama dengan berat fluida yang dipindahkan oleh benda. Dengan demikian diperoleh hubungan berikut.

$$
\rho_{b}=\frac{v_{b f}}{v_{b}} \rho_{f}
$$


dimana : $\mathrm{Fa}=$ gaya ke atas $(\mathrm{N}), \mathrm{W}=$ gaya berat benda $(\mathrm{N}), \mathrm{v}_{\mathrm{bf}}=$ volume benda yang tercelup dalam fluida $\left(\mathrm{m}^{3}\right), \mathrm{v}_{\mathrm{b}}=$ volume benda seluruhnya $\left(\mathrm{m}^{3}\right), \rho_{\mathrm{f}}$ $=$ massa jenis fluida $\left(\mathrm{kg} / \mathrm{m}^{3}\right)$ dan $\rho_{\mathrm{b}}=$ massa jenis benda $\left(\mathrm{kg} / \mathrm{m}^{3}\right)$

\section{Tekanan}

Tekanan didefinisikan sebagai gaya per satuan luas [4], dimana gaya $\mathrm{F}$ bekerja secara tegak lurus terhadap luas permukaan A suatu zat (padat, cair, gas), maka dapat dirumuskan sebagai berikut.

$$
p=\frac{F}{A} \text {....... }
$$

Dimana, $\mathrm{p}=$ tekanan $(\mathrm{N} / \mathrm{m} 2), \mathrm{F}=$ gaya normal $(\mathrm{N})$, $\mathrm{A}=$ luas permukaan kontak gaya normal (m2).

Apabila suatu benda berada pada kedalaman $h$ tertentu di bawah permukaan cairan seperti yang ditunjukkan pada Gambar 3, maka berat benda membuat cairan tersebut mengeluarkan tekanan. Tekanan yang dipengaruhi oleh kedalaman zat cair ini disebut dengan tekanan hidrostatis.

Apabila suatu benda berada pada kedalaman h tertentu di bawah permukaan cairan seperti yang ditunjukkan pada Gambar 3, maka berat benda membuat cairan tersebut mengeluarkan tekanan. Tekanan yang dipengaruhi oleh kedalaman zat cair ini disebut dengan tekanan hidrostatis.

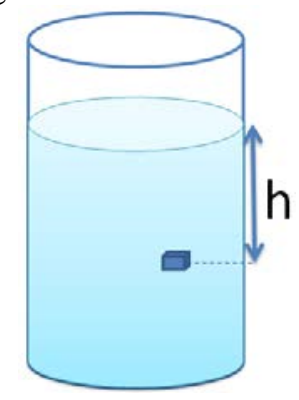

Gambar 3. Tekanan pada kedalaman h dalam cairan

[1].

Gaya yang bekerja pada luasan tersebut adalah $\mathrm{F}=$ $\mathrm{mg}=\rho \mathrm{A}_{\mathrm{h}} \mathrm{g}$, dengan $\mathrm{A}_{\mathrm{h}}$ adalah

percepatan gravitasi. Kemudian tekanan hidrostatis $\mathrm{P}_{\mathrm{h}}$ adalah

$$
p_{h}=\frac{F}{A}=\frac{m g}{A}=\frac{\rho A h g}{A}=\rho g h .
$$

Tekanan elemen volume pada kedalaman h relative terhadap permukaan adalah

$$
p=p_{o}+\rho g h \text {. }
$$

Dimana: $\mathrm{p}=$ Tekanan, $\mathrm{po}=$ tekanan permukaan, $\rho=$ massa jenis

Tekanan isotermis (Hukum Boyle $\mathbf{P V = K o n s t a n )}$ Dalam Tulisannya mengenai gas ideal, Robert Boyle (1627 - 1691) menggunaka tabung gelas berbentuk huruf $\mathrm{J}$, dengan merkuri di masukkan dalam tabung itu. Hasilnya dapat dielaborasi menjadi:

$$
\mathrm{p}_{1} \mathrm{v}_{1}=\mathrm{p}_{2} . \mathrm{v}_{2} .
$$

Dimana: $\mathrm{p}=$ Tekanan pada besaran tertentu dan $\mathrm{v}=$ volume pada besaran tertentu

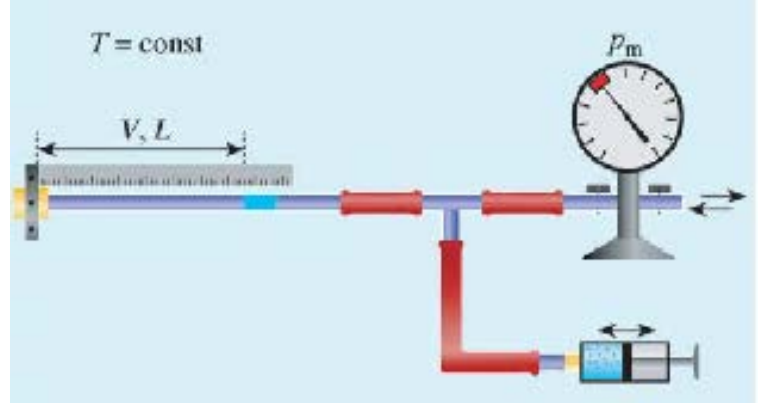

Gambar 4. Percobaan Hukum Boyle (pv=konstan)

Pada gambar 4, dapat dibuktikan bahwa jika piston ditekan pada temperature konstan sehingga volume dalam silinder berkurang dari $\mathrm{v}_{1}$ menjadi $\mathrm{v}_{2}\left(\mathrm{v}_{1}>\mathrm{v}_{2}\right)$, maka tekanan yang ditunjukkan oleh alat ukur akan meningkat dari $\mathrm{p} 1$ menjadi $\mathrm{p}_{2}\left(\mathrm{p}_{2}>\mathrm{p}_{1}\right)$.

\section{Macam-macam tekanan}

Tekanan mutlak (absolut/ATA) adalah tekanan gas yang sebenarnya yang dinytakan dalam psi;Tekanan aktual pada posisi tertentu disebut tekanan absolut dan diukur secara relatif terhadap tekanan vakum, yaitu tekanan nol mutlak.

Tekanan gage (tekanan atmosfir/ATM) adalah tekanan lebihnya dari tekanan udara luar atau atmosfir (psig);

Tekanan vakum (tekanan dalam tangki) adalah tekanan kurangnya dari tekanan udara luar atau atmosfir . Tekanan di bawah tekanan atmosfer disebut tekanan vakum (vacuum pressure) dan diukur dengan pengukur vakum yang menunjukkan perbedaan antara tekanan atmosfer dan tekanan absolut.

$$
\left.P_{\text {gage }}=P_{\text {abs }}-P_{\text {atm }} \quad \text { (untuk } P>P_{\text {atm }}\right)
$$

$$
P_{\text {vac }}=P_{\text {atm }}-P_{\text {abs }} \quad \text { (untuk } P<P_{\text {atm })}
$$

Tekanan gas di dalam tangki dapat dianggap seragam karena berat gas terlalu kecil dan tidak mengakibatkan pengaruh yang berarti. Skala tekanan vakum mempunyai titik nol pada tekanan atmosfir dan yang paling tinggi sama dengan zero absolute. Pengukuran tekanan absolut sangat penting dalam menentukan skala tekanan gage dan skala vakum untuk mengukur tekanan, baik tekanan gage, absolut, vakum ataupun beda tekanan (differential pressure), Perbedaan antara ATM dan ATA: Tekanan Atmosfir (ATM) adalah satuan tekanan setara dengan berat atmosfer bumidi permukaan laut. Tekanan Absolut (ATA-Atmospheres Absolut) adalah tekanan ambien total pada system yang dihitung atau diukur. Perbedaan tekanan absolut dan tekanan atmosfer 
disebut tekanan ukur (pressure gage). Perbedaan antara tekanan gage dengan tekanan absolut ialah pada titik nolnya. Titik nol untuk tekanan gage terletak pada tekanan atmosfir sedangkan untuk tekanan absolut terletak pada titik nol mutlak (zero absolute). ATA digunakan untuk menunjukkan bahwa tekanan mutlak mencakup penambahan 1 ATM ke pengukur tekanan yang dibaca.

\section{Head Statis pompa}

Head statis adalah penjumlahan head elevasi dengan head tekanan. Head statis dari head statis sisi masuk dan sisi keluar/tekan sebagai berikut

$$
\begin{aligned}
& H_{\text {Statis Isap }}=\left(Z+\frac{p}{\rho g}\right)_{1} \\
& H_{\text {Statis Tekan }}=\left(Z+\frac{p}{\rho g}\right)_{2}
\end{aligned}
$$

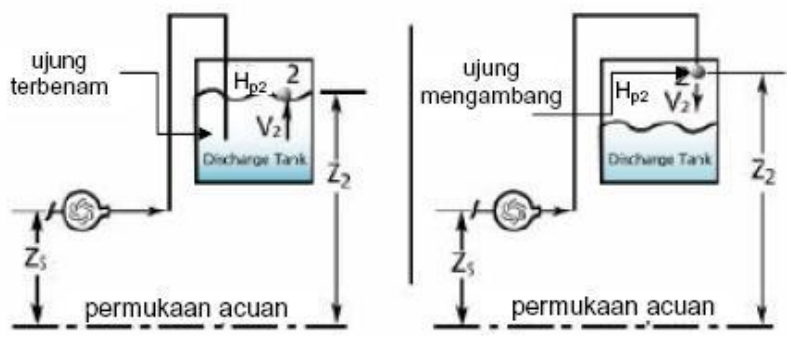

Gambar 5. Head statis discharge

Dimana Head total pompa adalah

$$
H_{\text {pompa }}=\left(\Delta Z+\Delta \frac{p}{\rho g}+\Delta \frac{v^{2}}{2 g}\right)+H_{\text {losses }} \ldots \ldots \ldots \ldots
$$

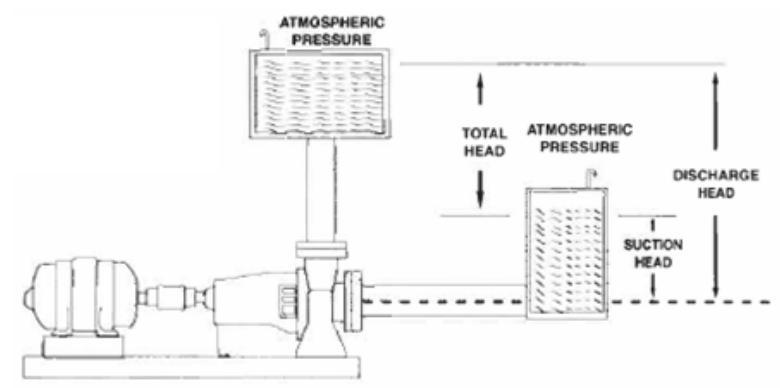

Gambar 6. Total head

Dalam memilih suatu pompa untuk maksud tertentu, terlebih dahulu harus diketahui aliran serta head yang diperlukan untuk mengalirkan zat cair yang akan dipompa. Head pompa adalah energi per satuan berat yang harus disediakan untuk mengalirkan sejumlah zat cair yang direncanakan sesuai kondisi instalasi pompa atau tekanan untuk mengalirkan sejumlah zat cair, yang umumnya dinyatakan dalam satuan panjang. Head dapat bervariasi pada penampang yang berbeda, tetapi pada kenyataannya selalu ada rugi energi. Head total pompa yang harus disediakan untuk mengalirkan jumlah air seperti direncanakan, dapat ditentukan dari kondisi instalasi yang akan dilayani oleh pompa.

$$
H_{\text {sis }}=h_{a}+h_{l}+\frac{v_{d}^{2}}{2 g} \text {. }
$$

Dimana: Hsis : Head sistem pompa (m), $\mathrm{h}_{\mathrm{a}}$ : Head statis total $(\mathrm{m}), \Delta \mathrm{h}_{\mathrm{p}}$ : Perbedaan head tekanan yang bekerja pada kedua permukaan $(\mathrm{m}), \Delta \mathrm{h}_{\mathrm{p}}=\mathrm{h}_{\mathrm{p} 2}-$ $\mathrm{h}_{\mathrm{p} 1}, \mathrm{~h}_{\mathrm{l}}$ : Berbagai kerugian head di pipa, katup, belokan, sambungan, dll (m) $\mathrm{h}_{1}=\mathrm{h}_{\mathrm{ld}}+\mathrm{h}_{\mathrm{ls}}, \mathrm{v}_{\mathrm{d}}^{2} / 2 \mathrm{~g}$ : Head kecepatan keluar (m), g : Percepatan gravitasi $\left(9,81 \mathrm{~m} / \mathrm{s}^{2}\right)$

\section{METODE PERHITUNGAN}

Agar diperoleh batas gaya dorong keatas maksimum oleh bouy (pelampung), maka berat air yang dipindahkan/isi air tank harus sama dengan volume bouy. Jadi perhitungan dimulai ketika air sudah melewati volume bouy dimana $\mathrm{h}=0$ (tinggi bouy) sebagaimana terlihat pada gambar model berikut ini,

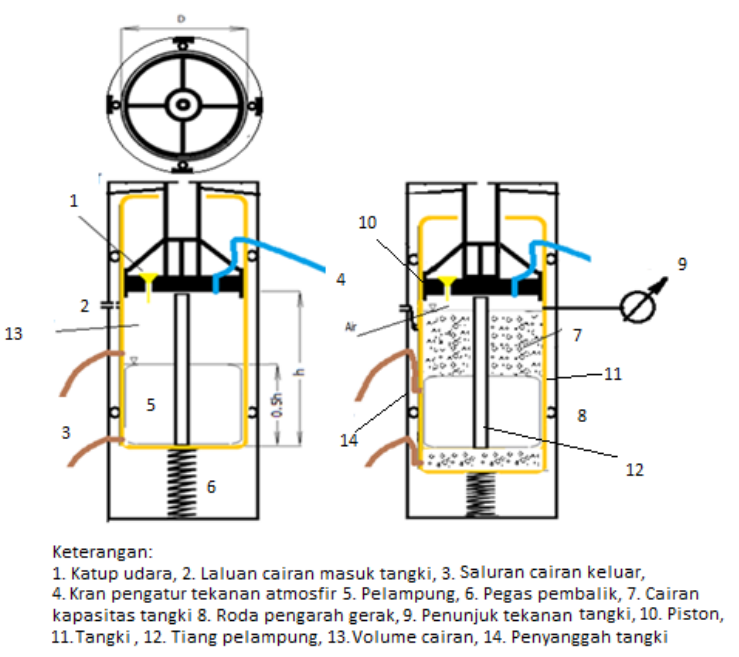

Gambar 7. Model tangki rancangan

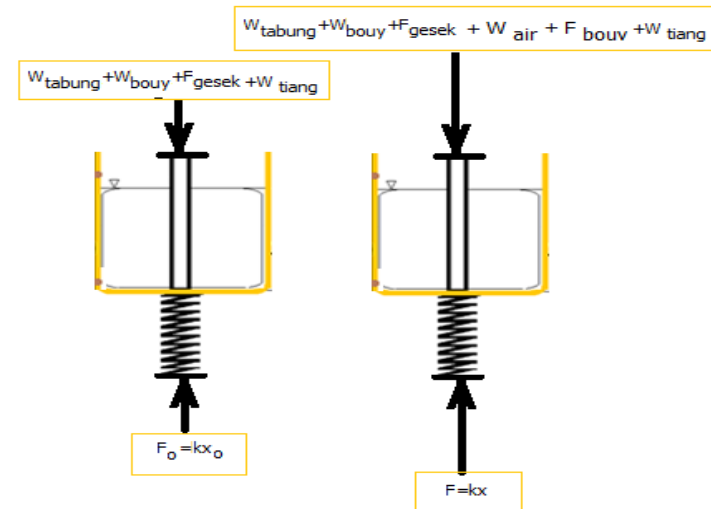

Gambar 8. Gaya-gaya yang diterima pegas pembalik yang digantikan oleh lengan pembalik.

Seiring dengan meningkatnya jumlah cairan yang masuk kedalam tangki, maka tekanan dalam tangki akibat pergerakan tangki tertutup kearah bawah akan mengikuti fenomena tekanan negatif, dimana 
volume air yang masuk adalah sama dengan volume udara yang keluar dikarangi volume yang terjadi akibat berat air ditambah dengan volume yang terjadi akibat gaya apung yang merupakan fenomena turunnya tangki (pergerakan tangki kebawah). Dengan demikian laju difleksi pegas harus lebih besar dari pada peningkatan laju tinggi air pada tank. Jika Q=laju volume air yang masuk kedalam tangki (liter/menit), maka tinggi cairan pada tangki sebesar laju volume air dikalikan dengan waktu alir dibagi luas penampang tangki, dimana lendutan pegas yang terjadi adalah total gaya kebawah dibagi dengan kekakuannya atau sama dengan kecepatan rata-rata kebawah dikalikan dengan waktu yang digunakan (makin tinggi permukaan cairan pada tangki makin besar pula lendutan pegas yang terjadi). Untuk mengoptimalkan efek gaya apung, maka tiang pelampung akan dibuat seringan mungkin. Dan untuk mengantisipasi penciutan tangki walau sangat kecil karena akan berpengaruh pada piston isap maka akan dipertimbangkan menggunakan cincin fleksibel seperti pada engine piston.

\begin{tabular}{|c|c|c|c|}
\hline $\mathrm{D}$ tank, $\mathrm{m}$ & 1.25 & $\begin{array}{c}\text { Luas } \\
\text { penampang } \\
\text { tank } \\
\mathrm{m}^{\wedge} 2\end{array}$ & 1.226563 \\
\hline Tinggi bouy, $\mathrm{m}$ & 2 & $\begin{array}{c}\text { Luas } \\
\text { penampang } \\
\text { bouy } \\
\mathrm{m}^{\wedge} 2\end{array}$ & 1.226563 \\
\hline $\begin{array}{c}\text { Diameter bouy, } \\
\mathrm{m}\end{array}$ & 1.25 & $\begin{array}{c}\text { Volume } \\
\text { awal tank } \\
\pi \mathrm{D}^{2} \mathrm{~h} / 4 \\
\mathrm{~m}^{\wedge} 3\end{array}$ & 4.90625 \\
\hline $\begin{array}{c}\mathrm{h} \text { tank, meter, } \\
\mathrm{m}\end{array}$ & 4 & $\begin{array}{c}\text { Volume } \\
\text { udara } \\
m^{\wedge} 3\end{array}$ & 2.453125 \\
\hline $\begin{array}{c}\text { Tebal plat bouy, } \\
\text { t meter }\end{array}$ & 0.003 & $\begin{array}{c}\text { Volume } \\
\text { Bouy } \\
\mathrm{m}^{\wedge} 3\end{array}$ & 2.453125 \\
\hline $\begin{array}{l}\text { Berat jenis } \\
\text { bouy, } \mathrm{kg} / \mathrm{m}^{3}\end{array}$ & 300 & $\begin{array}{c}\text { Volume air } \\
\text { penuh } \\
\mathrm{m}^{\wedge} 3 \\
\end{array}$ & 2.453125 \\
\hline $\begin{array}{l}\text { Berat jenis air, } \\
\mathrm{kg} / \mathrm{m}^{3}\end{array}$ & 1000 & $\begin{array}{c}\text { Volume air } \\
\text { penuh } \\
\text { Liter }\end{array}$ & 2453.125 \\
\hline Berat bouy, $\mathrm{kg}$ & $\begin{array}{c}2357.207 \\
813\end{array}$ & $\begin{array}{c}\text { Gaya total } \\
\text { bouy } \\
\text { kg }\end{array}$ & 2453.125 \\
\hline Pegas & & $\begin{array}{c}\text { Konstanta } \\
\text { pegas } \\
\mathrm{kg} / \mathrm{m}\end{array}$ & 1900 \\
\hline
\end{tabular}

\section{PERHITUNGAN}

Data masukan

\section{Luaran}

\begin{tabular}{|c|c|c|c|c|c|c|c|c|c|c|}
\hline \multicolumn{11}{|c|}{ PARAMETER } \\
\hline $\mathrm{h}$ & $\begin{array}{c}\text { Volume } \\
\text { air=volu } \\
\text { me } \\
\text { udara } \\
\text { yang } \\
\text { keluar, } \\
\mathrm{m}^{\wedge} 3\end{array}$ & $\begin{array}{c}\text { Gaya } \\
\text { dorong } \\
\text { kebawah } \\
\text { oleh air }\end{array}$ & $\begin{array}{l}\text { Gaya } \\
\text { dorong ke } \\
\text { atas oleh } \\
\text { bouy }\end{array}$ & $\begin{array}{l}\text { Total gaya } \\
\text { kebawah }\end{array}$ & $\begin{array}{c}\text { Gaya } \\
\text { Gese } \\
\text { k+Ber } \\
\text { at } \\
\text { tiang+ } \\
\text { W } \\
\text { bouy }\end{array}$ & $\begin{array}{l}\text { Net gaya } \\
\text { ke bawah }\end{array}$ & $\begin{array}{c}\text { Net gaya } \\
\text { kebawah, } \\
\text { tinggal } \\
\text { hanya oleh } \\
\text { bouy-(Gaya } \\
\text { gesek+Bera } \\
\text { t batang) }\end{array}$ & $\begin{array}{l}\text { Tekanan } \\
\text { kebawah }\end{array}$ & $\begin{array}{c}\text { Tekanan } \\
\text { udara/air, } \\
\text { kg/m^2 }\end{array}$ & $\begin{array}{c}\text { Tekanan, } \\
\mathrm{h}(\mathrm{m})\end{array}$ \\
\hline 0 & 0 & 0 & 0 & 0 & 0 & 0 & 0 & 0 & 10332.27 & 10.33227 \\
\hline 0.1 & 0.1226 & 122.656 & 122.6562 & 245.3125 & 7 & 238.312 & 115.65625 & 94.29299 & 10237.98 & 10.2379 \\
\hline 0.2 & 0.2453 & 245.312 & 245.3125 & 490.625 & 7 & 483.625 & 238.3125 & 194.2929 & 10143.69 & 10.1436 \\
\hline 0.3 & 0.3679 & 367.968 & 367.9687 & 735.9375 & 7 & 728.937 & 360.96875 & 294.2929 & 10049.4 & 10.0494 \\
\hline 0.4 & 0.4906 & 490.625 & 490.625 & 981.25 & 7 & 974.25 & 483.625 & 394.2929 & 9955.103 & 9.95510 \\
\hline 0.5 & 0.6132 & 613.281 & 613.2812 & 1226.5625 & 7 & 1219.56 & 606.28125 & 494.2929 & 9860.81 & 9.86081 \\
\hline 0.6 & 0.7359 & 735.937 & 735.9375 & 1471.875 & 7 & 1464.87 & 728.9375 & 594.2929 & 9766.517 & 9.76651 \\
\hline 0.7 & 0.8585 & 858.593 & 858.5937 & 1717.1875 & 7 & 1710.18 & 851.59375 & 694.2929 & 9672.224 & 9.67222 \\
\hline 0.8 & 0.981 & 981.25 & 981.25 & 1962.5 & 7 & 1955.5 & 974.25 & 794.2929 & 9577.931 & 9.57793 \\
\hline 0.9 & 1.1039 & 1103.90 & 1103.906 & 2207.8125 & 7 & 2200.81 & 1096.9062 & 894.2929 & 9483.638 & 9.48363 \\
\hline 1 & 1.2265 & 1226.56 & 1226.562 & 2453.125 & 7 & 2446.12 & 1219.5625 & 994.2929 & 9389.345 & 9.38934 \\
\hline 1.1 & 1.3492 & 1349.21 & 1349.218 & 2698.4375 & 7 & 2691.43 & 1342.2187 & 1094.292 & 9295.052 & 9.29505 \\
\hline 1.2 & 1.4718 & 1471.87 & 1471.875 & 2943.75 & 7 & 2936.75 & 1464.875 & 1194.292 & 9200.759 & 9.20075 \\
\hline 1.3 & 1.5945 & 1594.53 & 1594.531 & 3189.0625 & 7 & 3182.06 & 1587.5312 & 1294.292 & 9106.466 & 9.10646 \\
\hline 1.4 & 1.7171 & 1717.18 & 1717.187 & 3434.375 & 7 & 3427.37 & 1710.1875 & 1394.292 & 9012.173 & 9.01217 \\
\hline
\end{tabular}




\begin{tabular}{|c|c|c|c|c|c|c|c|c|c|c|}
\hline 1.5 & 1.8398 & 1839.84 & 1839.843 & 3679.6875 & 7 & 3672.68 & 1832.8437 & 1494.292 & 8917.88 & 8.91788 \\
\hline 1.6 & 1.9625 & 1962.5 & 1962.5 & 3925 & 7 & 3918 & 1955.5 & 1594.292 & 8823.587 & 8.82358 \\
\hline 1.7 & 2.0851 & 2085.15 & 2085.156 & 4170.3125 & 7 & 4163.31 & 2078.1562 & 1694.292 & 8729.294 & 8.72929 \\
\hline 1.8 & 2.2073 & 2207.81 & 2207.812 & 4415.625 & 7 & 4408.62 & 2200.8125 & 1794.292 & 8635.001 & 8.63500 \\
\hline 1.9 & 2.3304 & 2330.46 & 2330.468 & 4660.9375 & 7 & 4653.93 & 2323.4687 & 1894.292 & 8540.708 & 8.54070 \\
\hline 2 & 2.4531 & 2453.12 & 2453.125 & 4906.25 & 7 & 4899.25 & 2446.125 & 1994.292 & 8446.415 & 8.44641 \\
\hline 2.1 & 2.5757 & 2575.78 & 2575.781 & 5151.5625 & 7 & 5144.56 & 2568.7812 & 2094.292 & 8352.122 & 8.35212 \\
\hline 2.2 & 2.6984 & 2698.43 & 2575.781 & 5274.2188 & 7 & 5144.56 & 2568.7812 & 2094.292 & 8257.829 & 8.25782 \\
\hline 2.3 & 2.8210 & 2821.09 & 2575.781 & 5396.875 & 7 & 5144.56 & 2568.7812 & 2094.292 & 8163.536 & 8.16353 \\
\hline 2.4 & 2.9437 & 2943.75 & 2575.781 & 5519.5313 & 7 & 5144.56 & 2568.7812 & 2094.292 & 8069.243 & 8.06924 \\
\hline 2.5 & 3.0664 & 3066.40 & 2575.781 & 5642.1875 & 7 & 5144.56 & 2568.7812 & 2094.292 & 7974.95 & 7.97495 \\
\hline 2.6 & 3.1890 & 3189.06 & 2575.781 & 5764.8438 & 7 & 5144.56 & 2568.7812 & 2094.292 & 7880.657 & 7.88065 \\
\hline 2.7 & 3.3117 & 3311.71 & 2575.781 & 5887.5 & 7 & 5144.56 & 2568.7812 & 2094.292 & 7786.364 & 7.78636 \\
\hline 2.8 & 3.4343 & 3434.37 & 2575.781 & 6010.1563 & 7 & 5144.56 & 2568.7812 & 2094.292 & 7692.071 & 7.69207 \\
\hline 2.9 & 3.5570 & 3557.03 & 2575.781 & 6132.8125 & 7 & 5144.56 & 2568.7812 & 2094.292 & 7597.778 & 7.59777 \\
\hline 3 & 3.6796 & 3679.68 & 2575.781 & 6255.4688 & 7 & 5144.56 & 2568.7812 & 2094.292 & 7503.485 & 7.50348 \\
\hline 3.1 & 3.8023 & 3802.34 & 2575.781 & 6378.125 & 7 & 5144.56 & 2568.7812 & 2094.292 & 7409.192 & 7.40919 \\
\hline 3.2 & 3.925 & 3925 & 2575.781 & 6500.7813 & 7 & 5144.56 & 2568.7812 & 2094.292 & 7314.899 & 7.31489 \\
\hline 3.3 & 4.0476 & 4047.65 & 2575.781 & 6623.4375 & 7 & 5144.56 & 2568.7812 & 2094.292 & 7220.606 & 7.22060 \\
\hline 3.4 & 4.1703 & 4170.31 & 2575.781 & 6746.0938 & 7 & 5144.56 & 2568.7812 & 2094.292 & 7126.313 & 7.12631 \\
\hline 3.5 & 4.2929 & 4292.96 & 2575.781 & 6868.75 & 7 & 5144.56 & 2568.7812 & 2094.292 & 7032.02 & 7.03202 \\
\hline 3.6 & 4.4156 & 4415.62 & 2575.781 & 6991.4063 & 7 & 5144.56 & 2568.7812 & 2094.292 & 6937.727 & 6.93772 \\
\hline 3.7 & 4.5382 & 4538.28 & 2575.781 & 7114.0625 & 7 & 5144.56 & 2568.7812 & 2094.292 & 6843.434 & 6.84343 \\
\hline 3.8 & 4.6609 & 4660.93 & 2575.781 & 7236.7188 & 7 & 5144.56 & 2568.7812 & 2094.292 & 6749.141 & 6.74914 \\
\hline
\end{tabular}

\begin{tabular}{|c|c|c|c|c|c|c|}
\hline \multicolumn{7}{|c|}{ TEORITIS } \\
\hline P1 & V1 & P2 & V2 & Difleksi, m & $\begin{array}{l}\text { Kenaikan tinggi } \\
\text { tekan, \% }\end{array}$ & $\begin{array}{l}\text { Tinggi maksimum, h- } \\
\text { delta max=tinggi air }\end{array}$ \\
\hline 10.33227 & 2.453125 & 10.23798 & 2.475719 & 0.01842 & 0.912606 & Belum penuh \\
\hline 10.23798 & 2.475719 & 10.14369 & 2.498732 & 0.018763 & 1.825213 & Belum penuh \\
\hline 10.14369 & 2.498732 & 10.0494 & 2.522178 & 0.019115 & 2.737819 & Belum penuh \\
\hline 10.0494 & 2.522178 & 9.955103 & 2.546067 & 0.019477 & 3.650425 & Belum penuh \\
\hline 9.955103 & 2.546067 & 9.86081 & 2.570414 & 0.019849 & 4.563032 & Belum penuh \\
\hline 9.86081 & 2.570414 & 9.766517 & 2.59523 & 0.020233 & 5.475638 & Belum penuh \\
\hline 9.766517 & 2.59523 & 9.672224 & 2.620531 & 0.020627 & 6.388244 & Belum penuh \\
\hline 9.672224 & 2.620531 & 9.577931 & 2.64633 & 0.021033 & 7.300851 & Belum penuh \\
\hline 9.577931 & 2.64633 & 9.483638 & 2.672641 & 0.021452 & 8.213457 & Belum penuh \\
\hline 9.483638 & 2.672641 & 9.389345 & 2.699481 & 0.021882 & 9.126064 & Belum penuh \\
\hline 9.389345 & 2.699481 & 9.295052 & 2.726866 & 0.022326 & 10.03867 & Belum penuh \\
\hline 9.295052 & 2.726866 & 9.200759 & 2.754812 & 0.022784 & 10.95128 & Belum penuh \\
\hline 9.200759 & 2.754812 & 9.106466 & 2.783337 & 0.023256 & 11.86388 & Belum penuh \\
\hline 9.106466 & 2.783337 & 9.012173 & 2.812458 & 0.023742 & 12.77649 & Belum penuh \\
\hline 9.012173 & 2.812458 & 8.91788 & 2.842196 & 0.024245 & 13.6891 & Belum penuh \\
\hline 8.91788 & 2.842196 & 8.823587 & 2.872569 & 0.024763 & 14.6017 & Belum penuh \\
\hline 8.823587 & 2.872569 & 8.729294 & 2.903598 & 0.025298 & 15.51431 & Belum penuh \\
\hline 8.729294 & 2.903598 & 8.635001 & 2.935305 & 0.02585 & 16.42691 & Belum penuh \\
\hline 8.635001 & 2.935305 & 8.540708 & 2.967712 & 0.026421 & 17.33952 & Belum penuh \\
\hline
\end{tabular}




\begin{tabular}{|r|r|r|r|r|r|c|}
\hline 8.540708 & 2.967712 & 8.446415 & 3.000843 & 0.027011 & 18.25213 & Belum penuh \\
\hline 8.446415 & 3.000843 & 8.352122 & 3.034721 & 0.027621 & 19.16473 & Belum penuh \\
\hline 8.352122 & 3.034721 & 8.257829 & 3.069374 & 0.028252 & 20.07734 & Penuh \\
\hline 8.257829 & 3.069374 & 8.163536 & 3.104826 & 0.028904 & 20.98995 & Penuh \\
\hline 8.163536 & 3.104826 & 8.069243 & 3.141108 & 0.02958 & 21.90255 & Penuh \\
\hline 8.069243 & 3.141108 & 7.97495 & 3.178247 & 0.030279 & 22.81516 & Penuh \\
\hline 7.97495 & 3.178247 & 7.880657 & 3.216275 & 0.031004 & 23.72777 & Penuh \\
\hline 7.880657 & 3.216275 & 7.786364 & 3.255224 & 0.031755 & 24.64037 & Penuh \\
\hline 7.786364 & 3.255224 & 7.692071 & 3.295128 & 0.032533 & 25.55298 & Penuh \\
\hline 7.692071 & 3.295128 & 7.597778 & 3.336023 & 0.033341 & 26.46558 & Penuh \\
\hline 7.597778 & 3.336023 & 7.503485 & 3.377945 & 0.034179 & 27.37819 & Penuh \\
\hline 7.503485 & 3.377945 & 7.409192 & 3.420935 & 0.035049 & 28.2908 & Penuh \\
\hline 7.409192 & 3.420935 & 7.314899 & 3.465032 & 0.035952 & 29.2034 & Penuh \\
\hline 7.314899 & 3.465032 & 7.220606 & 3.510282 & 0.036891 & 30.11601 & Penuh \\
\hline 7.220606 & 3.510282 & 7.126313 & 3.556729 & 0.037868 & 31.02862 & Penuh \\
\hline 7.126313 & 3.556729 & 7.03202 & 3.604421 & 0.038883 & 31.94122 & Penuh \\
\hline 7.03202 & 3.604421 & 6.937727 & 3.65341 & 0.03994 & 32.85383 & Penuh \\
\hline 6.937727 & 3.65341 & 6.843434 & 3.703749 & 0.041041 & 33.76644 & Penuh \\
\hline 6.843434 & 3.703749 & 6.749141 & 3.755494 & 0.042187 & 34.67904 & Penuh \\
\hline
\end{tabular}

\section{SIMPULAN}

Dari hasil perhitungan menunjukan bahwa penerapan gaya apung pada tangki zat cair yang terletak pada elevasi tertentu dari sumbu pompa memiliki potensi besar untuk meningkatkan Head statis tekan pompa atau dapat mereduksi konsumsi daya pada sisi discharge pompa hingga 100\% termasuk rugi-rugi pada sisi discharge dengan jalan memperbesar kapasitas tangki. Disamping itu untuk memperoleh efektifitas gaya apung yang terpakai, maka pemilihan material apung dan batang pendorong harus seringan mungkin. Disamping itu, ketika zat cair disalurkan dari tangki ke pemakaian, maka diperoleh tekanan yang lebih besar dari pada tangki konvensional akibat dorongan gaya apung yang berfungsi ganda. Dengan penggatian pegas pembalik dengan momen pembalik akan dihasilkan tekanan isap yang lebih tinggi kenaikan sebesar gaya balik pegas.

\section{DAFTAR PUSTAKA}

Tipler A. Paul, Fisika untuk Sains dan Teknik, Edisi ke tiga jilid I, Erlangga, Jakarta 1996

Series, 1987

Athur Beiser, Aplied Physics, Schaum

Buche F.j. Teori dan Soal-soal Fisika, Seri Buku Schaum, Erlangga, Jakarta, 1989
Jewett, Serway Fisika Untuk Sains dan Teknik, Buku 1 edisi 6 Salemba Teknika, Jakarta 2009

Halliday dan Resnick, Fundamental of Physics, 1987 